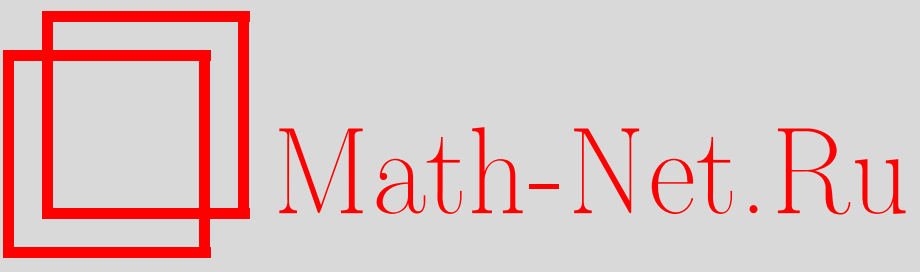

М.-М. Деза, М. И. Штогрин, Архимедовы полициклы, УМН, 2004, том 59, выпуск $3,165-166$

DOI: https://doi.org/10.4213/rm746

Использование Общероссийского математического портала Math-Net.Ru подразумевает, что вы прочитали и согласны с пользовательским соглашением

http://www.mathnet.ru/rus/agreement

Параметры загрузки:

IP : 54.162 .85 .209

26 апреля 2023 г., 11:48:49 


\title{
АРХИМЕДОВЫ ПОЛИЦИКЛЫ
}

\author{
М. ДЕЗА, М. И. Штогрин
}

Назовем $(r, q)$-полиииклом, $r \geqslant 3, q \geqslant 3$, двумерное многообразие, склеенное из $r$-угольников так, что степени внутренних вершин равны $q$, а степени граничных вершин $\leqslant q$. Назовем $(r, q)$ полицикл обычнылм, если он плоский и просто-связный. В [1]-[6] мы изучали обычные (не только конечные, но и бесконечные) полициклы. Любой из них является клеточным комплексом, см. [6] (клетки замкнуты [7]). Назовем $(r, q)$-полицикл $P$ соответственно $i$ - изогональнылм, $j$ - изо әдральньцм, $k$-изотоксальным (коротко $i$-IG,$j$-IH, $k$-IT), если группа Aut $P$ имеет всего $i$ орбит на вершинах, $j$ орбит на гранях, $k$ орбит на ребрах. Ясно, что 1 -IG влечет $j$-IН и $k$-IT с $j, k \leqslant q$, 1 -IН влечет $k$-IT и $i$-IG с $k, i \leqslant r, 1$-IT влечет $i$-IG и $j$-IН с $i, j \leqslant 2$. Вместе с $(r, q)$-полициклом $P$ неразветвленная накрывающая $\widetilde{P}$ также является $(r, q)$-полициклом. Накрьвающее отображение $\varphi: \widetilde{P} \rightarrow P$ и нетривиальньй автоморфизм $h: P \rightarrow P$ порождают накрывающее отображение $h \varphi$ (сначала $\varphi$, затем $h$ ). Если накрьвающая является универсальной, т.е. $\widetilde{P}=\widehat{P}$, то в силу ее единственности существует такой автоморфизм $\widehat{h}: \widehat{P} \rightarrow \widehat{P}$, при котором $h \varphi=\varphi \widehat{h}$. Представим полицикл $P$ как факторизацию универсальной накрьвающй $\widehat{P}$ по ее группе сколжжений $\widehat{N}$. Получим Aut $P \simeq \widehat{H} / \widehat{N}$, где $\widehat{H}$ - нормализатор группы $\widehat{N}$ в группе Aut $\widehat{P}$. Полицикл $P$ (относительно группы $H=$ Aut $P$ ) является $i$-IG, $j$-IH, $k$-IT в точности с теми же значениями $i, j, k$, что и полицикл $\widehat{P}$ относительно группы $\widehat{H} \subseteq$ Aut $\widehat{P}$. Назовем $(r, q)$-полицикл $P$ nравильнылм, если он 1-IG, 1-IН, 1-IT одновременно. Ясно, что отдельньй $r$-угольник является обычным правильньм $(r, q)$-полициклом с особым параметром $q=2$ (это моноцикл); все разбиения $\left(r^{q}\right)$ суть ${ }^{1}$ правильные $(r, q)$-полициклы, причем они обычные в случае плоскости и необычные в случае сфферы; назовем их тривиальными полициклами.

Теорема 1. Все вершинь правильного нетривиального полицикла внутренние.

Лишь 9 правильных полициклов - 5 платоновых тел и 4 разбиения проективной плоскости накрьваются сферой. Универсальная накрывающая любого другого $(r, q)$-полицикла является обычным полициклом. В частности, если полицикл $P$ обычный, то $\widehat{P}=P$. Если же $(r, q)$-полицикл $P$ не является обычным или одним из указанных 9 , то универсальная накрывающая $\widehat{P}$, ее группа скольжений $\widehat{N}$ и группа Aut $\widehat{P}$ являются бесконечными.

Данная заметка посвящена архимедовым, т.е. 1-изогональньм, $(r, q)$-полициклам.

Теорема 2. Реберный остов произвольного объчного нетривиального архимедова $(r, q)$-поличикла представляет собою бесконечный внешнепланарный граф.

Если все вершины архимедова $(r, q)$-полицикла $P$ являются внутренними (сюда относятся все нетривиальные регулярные полициклы), то он представляет собою конечную или бесконечную поверхность без края. Его универсалшная накрывающая $\widehat{P}$ имеет вид $\left(r^{q}\right)$. Группа $\operatorname{Aut}\left(r^{q}\right)$ есть коксетеровская группа $T^{*}(2, q, r)$. Теперь о перечислении. Пусть $\widehat{H}$ - некоторая подгруппа группы $T^{*}(2, q, r)$, транзитивная на вершинах разбиения $\left(r^{q}\right)$, а $\widehat{N}$ - некоторый ее нормальньй делитель без кручения. Тогда факторизация полиэдра $\widehat{P}=\left(r^{q}\right)$ по группе $\widehat{N}$ представляет собою некоторый $(r, q)$-полицикл $P$. И так получаются все $P$. Примерами таких $(r, q)$-полициклов служат поверхности "регулярных тороидов", данных в работе [8]: на рис. 2 (полиэдр Чазара), 8, 9а, 16 (карта Хивуда) все они 1-IG, 1-IH, 1-IT; на рис. 1, 7, 9b, 10, 11, 12 они 1-IG, 1-IH, 2-IT; на рис. 13 и рис. 14 они 1-IG, 1-IH, 3-IT.

Если все вершины архимедова $(r, q)$-полицикла $P$ являются граничными (всякий такой нетривиальный полицикл является $k$-IT c $k \geqslant 2$ ), то он представляет собою конечную или бесконечную поверхность с краем. Связная компонента края есть цикл $C_{n}$ длины $n$, где $n=r$, или $r \neq n \leqslant \infty$.

Работа выполнена при финансовой поддержке Российского фонда фундаментальных исследований (грант № 02-01-00803), Фонда поддержки ведущих научных школ (грант НШ-2185.2003.1) и Программы фундаментальных исследований ОМН РАН "Современные проблемы теоретической математики".

${ }^{1}$ Через $\left(r^{q}\right)$ обозначаются правильные разбиения сферы и плоскости Евклида или Лобачевского. 
Заклеив отверстия полицикла $n$-угольниками, при $n=r$ мы получим описанньй выше архимедов $(r, q)$-полицикл без края с универсальной накрывающей $\left(r^{q}\right)$, а при $r \neq n \leqslant \infty$ получим некоторый архимедов полиэдр без края, чья универсальная накрывающая есть архимедово разбиение сфферы или плоскости. Наоборот, удаление граней возвращает нас к исходному полициклу. Операция удаления граней может быть применена для конструирования таких полициклов. Так, например, один из архимедовых $(4,4)$-полициклов получается из архимедова многогранника $\left(3.4^{3}\right)$ при удалении треугольных граней. Два архимедова $(4,4)$-полицикла получаются из квадратной решетки $\left(4^{4}\right)$ при удалении тех квадратов, центры которых составляют квадратную или ромбическую подрешетку индекса 4 . Универсальные накрывающие дают еще два архимедова $(4,4)$-полицикла. Среди их факторизаций содержатся все правильные $(4,4)$-полициклы с краем.

ТеОРема 3. Каждый обьиныьй нетривиальньй 1-IH, но не 1-IT, архимедов $(r, q)$-полицикл представляет собою универсальную накрывающую прав ильного разбиения, продьрявленного при усечении вершин, или боковой поверхности антипризмы.

Среди нетривиальных архимедовых $(r, q)$-полициклов с $(r, q)=(3,3),(3,4),(3,5),(4,3),(5,3)$ только 4 являются замкнутьми - это факторизации поверхностей октаэдра, куба, икосаэдра, додекаэдра по центральной симметрии. Все остальные обладают краем.

Теорема 4. Все нетривиальные архимедовы (4,3)-полициклы с краем суть:

(i) боковые поверхности п-угольных призм, $1 \leqslant n<\infty$, и их универсальная накрьвающая, $n=\infty($ при $n=1$ и $n=2$ это не квадрильяжи, при $n=4$ полицикл расширяем);

(ii) факторизачии поличиклов серии (i) при четных п по чентральной симметрии (неориентируемь, при $n=2 u n=4$ не квадрильяжи, при $n=4$ поличикл расииряем).

Теорема 5. Все нетривиальнье архимедовь $(3,4)$-полицикль с краем суть:

(i) боковые поверхности п-угольных антипризм и их универсальная накрывающая (при $n=1$ и $n=2$ это не триангулячии, при $n=3$ поличикл расширяем);

(ii) факторизачии полициклов серии (i) при $n \equiv 1(\bmod 2)$ по чентральной симметрии (неориентируемы, при $n=1$ и $n=3$ не триангуляции, при $n=3$ полищикл расширяем).

Теорема 6. Все нетривиальные архимедовы $(3,5)$-полициклы с краем суть:

(i) скрученные ${ }^{2}$ разбиения $\left(n^{3}\right)$ с удаленными п-угольньми гранями, $2 \leqslant n<\infty, u$ их универсальная накрывающая, $n=\infty$ (при $n=3$ поличикл расширяем $)$;

(ii) факторизачии полициклов серии (i) при $6 \leqslant n \leqslant \infty$ (они ориентируемь).

Факторизация додекаэдра - единственньй нетривиальный архимедов $(5,3)$-полицикл. Нетривиальных архимедовых $(3,3)$-полициклов нет. Любой архимедов $(r, q)$-полицикл с краем допускает каждую из трех метрик постоянной кривизны - локально сферическую, локально евклидову, локально гиперболическую. Замкнутый допускает только одну.

\section{СПИСОК ЛИТЕРАТУРЫ}

[1] М. Деза, М.И. Штогрин // УМН. 1999. Т. 54. №6. С. 159-160. [2] М. Деза, М.И. Штогрин // УМН. 2000. Т. 55. № 1. С. 179-180. [3] М. И. Штогрин // УМН. 2000. T. 55. № 2. C. 155-156. [4] M. Deza, M. I. Shtogrin // J. Geom. Phys. 2002. V. 40. № 3-4. Р. 302-319. [5] М. Деза, М.И. Штогрин // Труды МИАН. 2002. Т. 239. С. 127-145. [6] М. Деза, М. И. Штогрин. Метрика постоянной кривизны на полициклах // Матем. заметки (в печати). [7] Г. Зейферт, В. Трельфалль. Топология. М.-Л.: ОНТИ, 1938. [8] L. Szilassi // Symmetry Cult. Sci. 2000. V. 11. № 1-4. P. 317-335.

LIGA, ENS, Paris and Institute of Statistical Mathematics, Tokyo; Математический институт им. В. А. Стеклова РАН

Принято редколлегией E-mail: Michel.Deza@ens.fr, stogrin@mi.ras.ru

01.04 .2004

\footnotetext{
${ }^{2}$ Случаи $n=3,4,5$ соответствуют известным скрученньм тетраэдру, кубу, додекаэдру.
} 